\title{
PALEOCEANOGRAPHIC SETTING OF THE UPPER TRIASSIC LUNING FORMATION (NEVADA) AND IMPLICATIONS FOR THE DISTRIBUTION OF SHONISAURUS (DIAPSIDA: ICHTHYOSAURIA)
}

MONTAGUE-JUDD*, Danielle, Dept. of Geosciences, University of Arizona, Tucson, AZ 85721, U.S.A.; PARRISH, Judith Totman, Dept. of Geosciences, University of Arizona, Tucson, AZ 85721, U.S.A.

The Upper Triassic Luning Formation at Berlin-Ichthyosaur State Park (BISP), Nevada, contains numerous ichthyosaur and invertebrate remains. Partial remains of more than 35 ichthyosaurs of the genus Shonisaurus have been found within a few square miles in and around the park. The question remains as to the specific paleoceanographic setting in which these large animals (up to 15 meters long) were deposited.

One explanation for the ichthyosaur fossil abundance is that high productivity fostered numerous prey organisms that could support large numbers of top predators such as Shonisaurus. The presence of abundant top predators, potential prey, and geochemical and lithologic features can be used as evidence of a high productivity environment. This study integrates paleobiologic, paleoecologic, geochemical, and petrographic data in order to formally test the idea that the Luning Formation was deposited in a high-productivity system.

The marine part of the Luning Formation at BISP (about 700 meters) contains several lithologies ranging from silty wackestone to calcareous shale to fairly pure limestone. Geochemical and petrographic data were collected in order to test for characteristics of high-productivity systems. Organic carbon and phosphate analyses were conducted on samples from representative lithologies throughout the section. Thin sections, slabs, and peels revealed features such as trace fossils that were obscured on weathered surfaces.

Changes in invertebrate communities and in ichthyosaur preservation (type and abundance), as well as in lithology, occur through the section. Temporal and/or spatial fluctuations in productivity during Luning deposition could have contributed to these changes. 